\title{
Do ensino remoto emergencial ao ensino híbrido no curso de ciências biológicas: a nossa visão a partir do Instituto de Biociências da Universidade de São Paulo (IB-USP)
}

\author{
From emergency remote teaching to quality blended learning: our view \\ from the Institute of Biosciences at University of São Paulo (IB-USP)
}

Fungyi Chow ${ }^{1}$ (D), Cristiane Paula Gomes Calixto ${ }^{1}$ (D), Marco Aurelio Ribeiro Mello ${ }^{1}$

\begin{abstract}
RESUMO
A formação de biólogos baseia-se fortemente em um currículo presencial, incluindo inúmeras atividades práticas de laboratório e campo. Essa estrutura foi abruptamente abalada pela pandemia em 2020, forçando-nos a uma mudança para o ensino remoto emergencial (ERE). Sobrevivemos e nos adaptamos. Agora é hora de refletirmos com calma sobre a nossa prática docente. Que tal aproveitar o que aprendemos no calor da batalha e pensar em uma futura evolução do ERE para o ensino híbrido no curso de Ciências Biológicas do IB-USP? Assim como ocorre evolução biológica e cultural, é natural que a nossa prática docente e o processo de ensino-aprendizagem também evoluam. Cometemos erros e acertos, e as nossas experiências oferecem uma oportunidade de abraçar o processo de adaptação e evoluir. É importante ressaltar que o hibridismo em um curso de Ciências Biológicas, por definição, não envolve abolir experiências práticas presenciais que fomentem habilidades e competências fundamentais para a atuação profissional de biólogos. Não defendemos aqui uma migração integral para a educação a distância (EAD) ou os cursos abertos online em massa (MOOC), mas a incorporação de aprendizados e ferramentas obtidos durante o ERE. O ensino híbrido, além de valorizar significado e contexto, pode facilitar que cada aluno estabeleça o seu próprio ritmo de estudo. Ele permite ao estudante um papel ativo na aprendizagem autônoma e na exploração de novos conteúdos, dentro de limites de organização e prazos de aprendizado. Isso pode ainda aumentar o aproveitamento das atividades práticas de laboratório e campo, e de outras que são mais produtivas em modo presencial. O ensino híbrido, com boa parte do conteúdo passada de forma remota, torna a experiência de aprendizagem mais agradável e possibilita a construção do conhecimento de forma mais colaborativa, ativa e integrativa. É notório que estamos enfrentando um dos maiores desafios da nossa era. Felizmente, temos a oportunidade de unir as nossas experiências e aumentar a eficiência do processo ensino-aprendizagem, assim como promover uma maior inclusão e acolhimento nas nossas turmas.
\end{abstract}

Palavras-chave: Educação à distância; Educação remota; Ensino online; Ensino híbrido, Tecnologia educacional; Covid-19

\begin{abstract}
The training of biologists is strongly based on a face-to-face curriculum, including numerous hands-on laboratory and field activities. This structure was abruptly changed by the 2020 pandemic, forcing us to move to emergency remote teaching (ERT). We survived and adapted, and we can now seize the opportunity to reflect on our teaching practices. How about we take advantage of what we learned in the heart of the battle and think about adopting the blended learning approach in the course of Biological Sciences at IB-USP? Just as biological and cultural evolution occur; it is only natural that our teaching practices and the teaching-learning processes also evolve. We had hits and misses with ERT, and these experiences allowed us to embrace adaptation, transforming our teaching practices. Surely, adopting the blended learning approach in a biology course, by definition, does not involve abolishing hands-on activities that foster fundamental skills and competences of the professional biologist. Therefore, we do not advocate here for a full migration to distance education (DE) or massive open online courses (MOOC), but rather to the incorporation of educational technology tools, used during the ERT, within traditional place-based teaching methods. Crucially, blended learning has the potential to improve teaching practices in higher education courses.
\end{abstract}

${ }^{1}$ Universidade de São Paulo, Instituto de Biociências, SP, Brasil. 
For example, it allows each student to become an autonomous learner where they can establish their own pace of study and take an active role in the exploration of new content. As a consequence, this can increase student performance in hands-on laboratory and field activities, and other activities that are more productive in person. In blended learning, most of the content is passed on remotely, making the learning experience more enjoyable and enabling the construction of knowledge in a more collaborative, active and integrated way. In summary, it is clear that we are facing one of the greatest challenges of our era but, fortunately, we have the opportunity to combine our experiences and improve our teaching practices, while promoting social acceptance and inclusive classrooms.

Keywords: Distance education; Remote learning; Online teaching; Blended learning, Educational technology; Covid-19

\section{MENSAGENS PRINCIPAIS:}

A pandemia de Covid-19 forçou uma migração temporária para o ensino remoto emergencial

Aprendemos muito com a experiência emergencial após um ano e temos ainda décadas de experiência com EAD e MOOC no Brasil

É vantajoso integrar todas essas lições e experiências para promover uma evolução em direção ao ensino híbrido no curso de Ciências Biológicas do IB-USP

\section{ADAPTAÇÕES}

"Não é a mudança, mas sim a resistência à mudança, que causa sofrimento"

Shakyamuni Buddha

Adaptar-se não é fácil, ainda mais quando estamos falando de uma instituição com uma longa e riquíssima história. Contudo, em alguns momentos críticos, a mudança simplesmente nos atropela. Cabe a nós, então, aceitarmos essa mudança ou, inutilmente, lutarmos contra ela. Esta é a nossa realidade agora, como professores enfrentando uma mudança drástica para o ensino remoto emergencial (ERE) durante a pandemia da Covid-19, a doença causada pelo novo coronavírus (SARS-CoV-2).
Essa mudança atingiu fortemente o curso de graduação em Ciências Biológicas do Instituto de Biociências da Universidade de São Paulo (IB -USP), inaugurado em 1934 como um curso de Ciências Naturais. Em 1957, ele foi reestruturado como um curso de História Natural. Só depois, em 1963, ele se consolidou como um curso de Ciências Biológicas. Ao longo da nossa longa história, a grade curricular do curso passou por muitas alterações, a fim de adaptar a cada tempo a formação de profissionais competentes e capacitados para o mercado de trabalho.

É importante salientar que a formação de biólogos se baseia fortemente em um currículo presencial, com uma alta porcentagem de atividades práticas de laboratório e de campo. Essa estrutura foi repentinamente abalada quando se decretou oficialmente a pandemia em março de 2020. A reitoria da USP e a diretoria do IB responderam prontamente, promovendo uma mudança para o trabalho remoto por tempo indefinido. Assim, as disciplinas presenciais em andamento tiveram que se moldar abruptamente ao ensino remoto emergencial. Não foi uma realidade exclusiva do IB-USP, mas sim um apavorante filme distópico em escala global. Não está sendo fácil para ninguém.

Sobrevivemos ao desespero inicial da emergência e adaptação. Agora podemos refletir com mais calma. A nossa prática docente se viu abalada na tentativa de abraçar o ensino remoto, com o qual poucos de nós têm familiaridade. Assim como os coronavírus evoluíram, também fomos forçados a nos reinventar e evoluir. Portanto, em analogia à evolução biológica, que ocorre por uma combinação entre mutação e pressão seletiva, fixando mecanismos adaptativos, gostaríamos de propor uma reflexão. Que tal pensarmos em uma futura evolução do ensino remoto emergencial para o ensino híbrido no curso de Ciências Biológicas do IB-USP?

\section{EVOLUÇÕES}

$\mathrm{Na}$ evolução biológica ocorrem diversos processos de mutação e adaptação, sendo que o mesmo ocorre na evolução cultural. Portanto, é natural que a nossa prática docente e o processo 
de ensino-aprendizagem também mudem com o tempo. É uma resposta esperada a pressões seletivas, que também mudam com o tempo.

Com a pressão imposta pela pandemia, a nossa primeira reação foi transformar as nossas aulas presenciais em videoaulas. Essa transformação emergencial sofreu enormes limitações didáticas, especialmente pela combinação de prazos apertados com a falta de capacitação de muitos professores em ensino remoto e mídias digitais. Isso, sem contar que muitos alunos não têm uma boa infraestrutura de estudo remoto em casa. Pior ainda foi quebrar as nossas cabeças para traduzirmos para o ensino remoto as nossas aulas práticas, saídas de campo, avaliações e trocas entre alunos e professores. No calor da batalha, cometemos erros e acertos, e aprendemos com a experiência prática em tempo acelerado.

Agora, um ano e muita experiência depois, surge a oportunidade de fazermos uma reflexão crítica sobre a nossa prática docente. Cabe ressaltar que o que estamos fazendo agora, durante a pandemia, é ensino remoto emergencial e não educação à distância (EAD) no sentido estrito ${ }^{1}$, nem outros formatos remotos, como ensino online aberto em massa (em inglês, massive online open courses - MOOC). Nossa meta tem sido minimizar perdas na aprendizagem, frente a uma situação de semi-quarentena ou semi-lockdown. Também lutamos para preservar os prazos acadêmicos dos quais os alunos dependem para se formar ou seguir rumo à conclusão do curso. Nessa situação, todos tentamos fazer o nosso melhor para lidar com a frustração e com as perdas. Infelizmente, é de se esperar que haja sequelas educacionais para estudantes e professores tanto no processo de aprendizado, quanto nas habilidades adquiridas, com impactos gerais na formação.

Porém, devemos olhar o lado positivo de tudo isso, abraçar o processo de adaptação e evoluir, por exemplo, adotando o ensino híbrido, ou seja, uma mistura entre presencial e remoto, no qual parte das atividades didáticas é realizada à distância e outra em sala de aula ${ }^{3}$ (hybrid ou blended learning). Esse tipo de ensino pode ser uma excelente chave para aprimorar a nossa prática docente, assim como aperfeiçoar os processos de ensino-aprendizagem de forma mais dinâmica e ativa. A adoção do ensino híbrido pode ser a mudança de formato que faltava para avançarmos na expansão da pedagogia ativa, baseada em estratégias como a sala de aula invertida, aprendizado com os pares e aprendizado orientado por projetos.

Da nossa experiência, podemos usar todo esse aprendizado de batalha para repensarmos a nossa pedagogia. Muitas soluções encontradas agora, na pandemia, podem continuar a ser usadas depois que a crise passar. Temos notado que algumas atividades, na verdade, melhoraram durante o ensino remoto ${ }^{2}$. Na verdade, desde antes de a internet ser aberta ao público no Brasil, nos anos 1990, já se discutiam vertentes para uma possível evolução do ensino superior para formatos híbridos.

É importante ressaltar a questão do hibridismo, no contexto de um curso de Ciências Biológicas. Isso porque atividades presenciais precisam necessariamente constar no currículo. Não dá para imaginar biólogos saindo para o mercado de trabalho sem passarem por experiências como saídas de campo, trabalho em lupa e microscópio, triagem de material biológico, entrevistas com o público, prática de ensino em escolas, atividades experimentais em bancada de laboratório, e muitas outras. Experiências práticas como essas fomentam habilidades e competências fundamentais para a atuação profissional de biólogos. Práticas pedagógicas presenciais são importantes para o desenvolvimento de habilidades propiciadas pelo contato pessoal. Logo, não defendemos aqui uma migração integral para EAD, mas a incorporação de aprendizados obtidos durante o ERE.

\section{TRANSIÇÕES}

Naturalmente, precisamos de cautela e planejamento nessa evolução rumo ao ensino híbri$\mathrm{do}^{4}$. Primeiro, porque o uso dos vários recursos digitais disponíveis hoje em dia depende da capacitação dos professores. Essa capacitação precisa ser atualizada regularmente, pois a tecnologia evolui cada vez mais rápido, tornando difícil para a maioria acompanhar as novidades em tempo real. Segundo, porque é preciso muito diálogo e conscientização para construirmos uma cultura de ensino na qual os professores não são mais 
os guardiões do conhecimento, mas sim orientadores do processo de aprendizado, que deve ser protagonizado pelos alunos.

Essa evolução, portanto, precisa ocorrer de forma gradual, de acordo com a capacitação e a disposição de cada professor, considerando também a infraestrutura de cada instituição de ensino e o perfil socioeconômico e demográfico dos alunos. Uma primeira barreira é a grande resistência que muitos colegas têm ao ensino remoto e à pedagogia ativa. Somos, na grande maioria, professores treinados no século $X X$, com métodos do século XIX, ensinando alunos do século XXI. Logo, além do choque de gerações, natural em qualquer contexto de ensino, ainda temos um grande choque de cultura a vencer.

O lado bom é que os professores, em sua maioria, dominam o conteúdo a ser ensinado. A maioria é criativa, aberta ao debate e preocupada com o aprendizado. Seria uma questão então de apresentar aos colegas as vantagens de outras formas de conduzir o processo de ensino -aprendizagem, além de capacitá-los em novas tecnologias que facilitem a implementação de novas pedagogias.

Na USP, notamos que vivemos uma realidade mais favorável ao ensino híbrido, em comparação a outras instituições nacionais de ensino superior. Conforme reportado no relatório da Comissão de Graduação do IB-USP, que recebeu respostas de 249 alunos após o primeiro semestre de 2020, o ensino remoto emergencial teve um saldo geral positivo.

Notamos nos resultados desse relatório que, pelo menos na nossa unidade, a grande maioria dos alunos vem das classes socioeconômicas $A$ e $B$. Isso se reflete no amplo acesso que eles têm a dispositivos eletrônicos, como notebooks, tablets e smartphones, além de acesso à internet. Contudo, a proporção de alunos vindos de classes menos favorecidas vem crescendo nos últimos anos na USP, graças a ações afirmativas. Isso deve nos deixar alertas para a necessidade futura de prover a infraestrutura necessária ao ensino híbrido aos alunos que não a tiverem em casa. Muitos alunos, de fato, vêm contando com o empréstimo de notebooks e modems de internet móvel feito pelo IB-USP para continuarem seus estudos durante esse primeiro ano de ensino remoto emer- gencial. Ainda assim, é importante alertar que muitos alunos relatam falta de estrutura adequada em casa, no qual devem dividir dispositivos eletrônicos com outros familiares, não contam com um espaço apropriado de estudo, ou dividem seu tempo com tarefas domésticas. Da mesma forma, a pandemia e o distanciamento físico vêm causando um impacto na saúde mental dos alunos, gerando ansiedade, falta de organização da rotina, depressão e estresse.

Quanto à decisão de não suspender o primeiro semestre de 2020 e prosseguir para o ERE, as opiniões se dividiram. Os alunos veteranos, em sua maioria, concordaram com a decisão, enquanto os ingressantes não a aprovaram. As respostas também divergiram entre veteranos e ingressantes, no que diz respeito ao aproveitamento das aulas remotas. Vale ressaltar que esses dados se referem apenas ao primeiro semestre, e que muitas melhorias foram feitas pelos professores e pela nossa coordenação no segundo semestre. Já no que diz respeito aos alunos conseguirem realizar as atividades remotas propostas, a maioria, em ambos os grupos, relatou não ter tido problemas.

Uma preocupação geral em ambos os grupos foram as avaliações e incertezas relacionadas. $\mathrm{Na}$ verdade, independentemente da pandemia, esse é um ponto sensível já há muitos anos. E esse ponto pode ser melhorado com o ensino híbrido, adotando-se uma filosofia baseada em avaliações diluídas ao longo do semestre. Deveríamos começar a usar diferentes formatos de avaliação, que aprofundam e consolidam o conhecimento, ao invés de gerar estresse acumulado desnecessário.

Precisamos levar em conta esse relatório, assim como o próximo que nos será divulgado, ao pensarmos sobre uma evolução para o ensino híbrido. Não podemos nos esquecer de que damos aulas para pessoas reais, de carne e osso, que vivem realidades distintas entre si. É fundamental que continuemos a aprender mais sobre essas realidades, de modo a personalizarmos a experiência de aprendizado tanto quanto possível.

\section{MOTIVAÇÕES}

O ensino híbrido pode ajudar muito a meIhorar o processo de ensino-aprendizagem, ainda 
mais se considerarmos os hábitos das gerações mais novas. Apesar de muito se discutir sobre a geração millennial (nascida entre 1980-1995), ela já deixou de ser nova e agora também compõe em grande parte o novo quadro docente das universidades. Assim, estamos pensando especificamente nas gerações iGen (1995-2010) e alpha (2010 até o presente), quando falamos em uma evolução para o ensino híbrido 5 .

O que caracteriza então os alunos iGen e alpha? Primeiro, são gerações nativas da revolução digital. Portanto, estamos falando de pessoas que cresceram em ambientes em que as vidas presencial e online se misturam profundamente. Além disso, são pessoas que consideram dispositivos como smartphones e tablets ferramentas que quase atingem um status de cyber-órgãos. Muitas delas têm contas em redes sociais desde a primeira infância. Essa vida híbrida gerou profundas mudanças culturais e cognitivas. Por exemplo, para alunos dessas gerações, passar horas e horas em sala de aula, assistindo passivamente a aulas expositivas, por mais bem preparadas que elas sejam, é quase uma tortura. Muitos desses alunos, hoje, consideram os vídeos como a principal mídia para aprender novas habilidades, desde cozinhar um bolo até como escrever um relatório ou plotar um diagrama de dispersão.

Pensando então sobre esses meios e hábitos, vale ressaltar que o ensino híbrido propicia a descentralização do processo de ensino. 0 professor passa a ser mais o orientador do processo e o aluno se torna protagonista para construir seu próprio modelo de aprendizagem. Aliás, como já é de praxe em cursos online, seja no formato EAD ou MOOC. Afinal de contas, o conteúdo teórico-prático deve fazer sentido para o estudante, possibilitando que seja incorporado como um conhecimento efetivo. Para o professor, tanto o histórico das mudanças do conhecimento científico como os conceitos já estão consolidados, mas para o aluno essa conexão pode não ser tão óbvia. Essa falta de conexão, associada aos formatos de avaliação clássicos, acaba levando muitos alunos a focarem apenas em decorar o conteúdo. Devemos lembrar que para um aprendizado efetivo, o conhecimento deve ter um significado que é individual e que é incorporado segundo nossas próprias experiências, caso contrário, "a ficha não cai".
Além de valorizar significado e contexto, o ensino híbrido pode, ainda, ajudar o aluno a estabelecer o seu próprio ritmo de estudo. Naturalmente, esse ritmo deve ocorrer dentro de certos limites de organização e prazos de aprendizado, a fim de poder avançar com novos conteúdos com toda a turma. Ao poder determinar seu próprio ritmo, fica mais fácil para os alunos potencializar o tempo e o espaço que eles têm disponíveis. Isso aumenta as chances de aproveitar melhor as experiências em atividades práticas de laboratório e campo, ou atividades que são mais produtivas de forma presencial. Assim, a aula expositiva pode ser transformada em conteúdo assíncrono a ser visto pelo aluno em um momento anterior ao encontro presencial. $O$ ensino híbrido fomenta, ain$\mathrm{da}$, uma aprendizagem colaborativa com os pares, permitindo que os alunos se organizem melhor, de acordo com suas realidades pessoais. Esse formato estimula que o estudante tenha um papel ativo em uma aprendizagem autônoma e na exploração de novos conteúdos. A maior flexibilidade desse formato fomenta também a comunicação, discussão e colaboração com os colegas, monitores e professores. Dessa forma, cada aluno pode direcionar seu aprendizado ao seu campo de interesse.

Outro fator importante a ser considerado, nessa questão da autonomia, são os diferentes perfis de pessoas que compõem as nossas turmas. Não somos todos iguais e uma clara diferença entre nós é o grau de extroversão. Como no ensino híbrido boa parte do conteúdo é passado de forma remota, a experiência de aprendizagem torna-se mais agradável para pessoas introvertidas e/ou autônomas, que preferem realizar algumas atividades sozinhas, no seu tempo. Além disso, o ensino híbrido permite que pessoas com necessidades especiais possam ser auxiliadas de forma mais individualizada.

\section{PERSPECTIVAS}

É notório que estamos enfrentando um dos maiores desafios da nossa era. Nesse contexto, vale lembrar que toda crise traz não apenas dor $\mathrm{e}$ destruição, mas também oportunidades de reinvenção e reconstrução. Aprendemos muito com este primeiro ano de ERE. E já tínhamos uma 
enorme experiência acumulada em iniciativas de EAD desenvolvidas há décadas, como o Telecurso Primeiro e Segundo Graus e a Universidade Virtual do Estado de São Paulo (Univesp). Mais recentemente, muitos de nós abraçamos também o ensino remoto mais individualizado, em massa, proporcionado pelo formato MOOC. Temos, portanto, diante de nós a oportunidade de unir todos esses mundos e tirar dessa união um novo formato que aumente, não apenas a eficiência do processo ensino-aprendizado, mas também a inclusão e o acolhimento nas nossas turmas.

\section{REFERÊNCIAS}

1. Hodges, C.; Moore, S.; Lockee, B.; trust, T.; Bond, A. 2020. The difference between emergency remo- te teaching and online learning. Educause Review, 27/03/2020. Disponível em: https://er.educause.edu/ articles/2020/3/the-difference-between-emergency-remote-teaching-and-online-learning

2. Heard, S. 2021. What if the way Covid-19 forces us to teach is actually better? Scientist Sees Squirrel, 18/01/2021. Disponível em: https://scientistseessquirrel.wordpress.com/2021/01/19/what-if-the-way-covid19-forces-us-to-teach-is-actually-better/

3. Valente, J.A. 2014. Blended learning e as mudanças no ensino superior: a proposta da sala de aula invertida. Educar em Revista (número especial 4): 79-97. Disponível em: https://dx.doi.org/10.1590/0104-4060.38645

4. Ursi, S.; Mello, M.A.R., Muylaert, R.L.; Palaoro, A.V. 2020. Sobrevivendo na Ciência e no ensino remoto. Live do blog Sobrevivendo na Ciência, 21/07/2020. Disponível em: https://youtu.be/nRrRu0og8PA

5. Twenge, J. 2018. iGen: why today's super-connected kids are growing up less rebellious, more tolerant, less happy - and completely unprepared for adulthood. Atria Books, New York. ISBN: 978-1501152016. 


\section{Participação dos autores:}

Todos os autores contribuíram na idealização, realização e revisão do manuscrito.

\section{Financiamento:}

FC foi financiada pelo Conselho Nacional de Desenvolvimento Científico e Tecnológico (CNPq 303493/2018-6), Fundação de Amparo à Pesquisa do Estado de São Paulo (FAPESP 2018/18015-8) e Pró-Reitoria de Graduação da Universidade de São Paulo (PRG-USP PUB 2020/258 e 2020/118).

CPGC foi financiada pela Fundação de Amparo à Pesquisa do Estado de São Paulo (FAPESP 2019/13158-8) e pelas Pró-Reitorias de Pesquisa (PRP-USP 20.1.4175.1.0) e de Graduação (PRG-USP PUB 2020/256), ambas da Universidade de São Paulo.

MARM foi financiado pela Fundação Alexander von Humboldt (AvH: 3.4-8151/15037 e 3.2-BRA/1134644), Conselho Nacional de Desenvolvimento Científico e Tecnológico (CNPq 304498/2019-0), Pró-Reitoria de Pesquisa da Universidade de São Paulo (PRP-USP 18.1.660.41.7) e Fundação de Amparo à Pesquisa do Estado de São Paulo (FAPESP 2018/20695-7).

\section{Agradecimentos:}

Agradecemos a todos os colegas, em todos os setores do sistema educacional, que estão enfrentando a batalha do ensino remoto emergencial durante a pandemia de Covid-19. A generosidade dessas pessoas tem levado a uma excelente troca de experiências em reuniões online, videochamadas, redes sociais, artigos, blogs e canais do YouTube. Também agradecemos a todos os alunos que têm demonstrado respeito e apreciação pelo esforço de adaptação dos professores neste momento crítico. Juntos somos mais fortes e venceremos um dos maiores desafios da nossa era.

Editor:

Prof. Dr. Marcelo Riberto

Recebido: $11 / 05 / 2021$

Aprovado: $13 / 07 / 2021$

(c) (i) Este é um artigo publicado em acesso aberto (Open Access) sob a licença Creative sem restrições, desde que prrabalho original seja corretamente citado. 